\title{
Perceptions of Communication Organizational - Family and Authentic Leadership
}

\author{
Paulus Eddy Suhartanto ${ }^{1, *}$, Markus Hartono ${ }^{2}$, Frikson Sinambela ${ }^{3}$ \\ ${ }^{1,3}$ Department of Psychology, University of Surabaya, Surabaya, Indonesia; \\ ${ }^{2}$ Department of Indutrial and Engineering, University of Surabaya, Surabaya, Indonesia; \\ *Corresponding e-mail: eddys_to@yahoo.com
}

\begin{abstract}
Research on authentic leadership antecedents is still limited. Several studies have shown that the role of psychological capital, self-knowledge and self-consistency is not consistent as antecedents of authentic leadership. Likewise related to the role perceptions of organizational and family communication as a mediator of authentic leadership. Understanding that the process of authentic leadership formation comes from internal processes but also depends on the organizational and family context. This study aims to examine the role of organizational and family communication perceptions as a mediator of authentic leadership models in group leaders. Collecting data using survey methods. Participants were 110 group leaders at a steel company in Bekasi, and Bakery, production and sales in Bandung. The results show that perceptions of organizational and family communication is not become a mediator on relationship between antecedents and authentic leadership. The benefit of this research is that it contributes to the integration of studies of authentic leadership models. It shows that the role of mediator is not supported. The limitations of the research are related to the measurement of organizational and family communication perceptions which have limited indicators, the implication is theoretically necessary to review the broader aspects of the organizational and family context as an understanding of organizational culture.
\end{abstract}

Keywords: Authentic leadership, Perception of organizational family communication, Antesedent.

\section{INTRODUCTION}

Many countries in the world are currently experiencing a major crisis in leadership in terms of politics, government, business, non-profit organizations, even in the fields of education and religion. Caza and Jackson explicitly termed a "global leadership crisis" to explain the scandals that occurred in corporations and politics around the world [1]. In Indonesia, it is pointed out that most organizations do not yet have a mature career or leadership succession plan in all organizational lines, and there is a lack of trust among organizational members in leaders [2]. Such challenges have the implication that effective leaders are needed. It takes a leader who understands the problem in a contextual manner, is aware of the strengths and weaknesses of himself and others and has integrity.

The harmony of what is said and done by the leader is important in order to build the trust of subordinates. This harmony can arise, among other things, if the individual as a leader can understand himself (weaknesses and strengths).

This understanding will make it easier for individuals a leaders to be more open, thus helping the process of building trust between superiors and subordinatesIn this regard, authentic leadership studies show a growing development as shown by various studies both in the western and eastern world (cultural dichotomy). For example, several research studies have been carried out in various countries such as America [3], Australia [4], Belgium [5], Brazil [6], Germany [7], Nigeria [8], Taiwan [9] and 
Indonesia [10]. This shows that interest and attention to this topic is still growing in Indonesia and outside Indonesia. There are very limited studies related to the antecedents of authentic leadership. Based on searches on google.com and google scholar with the keyword "antecedent s of authentic leadership", there are only a few studies that are related to a more comprehensive model (antecedents and consequences) [11], [12].

Therefore, this study will choose selfknowledge and self-consistency as antecedents. The selection of self-knowledge and self-consistency can also be seen as part of understanding an intrapersonal perspective, therefore these variables are variables that still need to be deepened, especially in a different cultural context. . In this cultural context, the role of communication within the organization and in the family also influences the formation of authentic leadership [13].

The determination of psychological capital is chosen based on the understanding of the concept that in the interpersonal process the capacity or psychological capacity model exists in the individual and can form individual authentic leadership. Besides, the perception of communication in organizations and families, as part of understanding the process of leadership formation, is a factor that needs to be considered.

Based on the problems described above, the main statement to be answered through this research is what are the antecedents and the role of communication in organizations and families to become authentic leadership mediators.

\section{METHOD}

The identification of research variables is carried out based on the hypotheses compiled in this study. The endogenous variable of this research is authentic leadership. The exogenous variables of this study include Self knowledge, Self Consitency and Psychological capital. Perceptions of organizational and family communication as a mediating variable.

This study is to measure leadership that involves leaders at the level of team leaders (unit heads, department heads, assignment team heads). Therefore, this study needs to be used by organizations that have many work units or group units. Respondent criteria, namely employee status is permanent employee; Minimum work period of 2 years, minimum high school education, and maximum age of 60 years.

The selection of research respondents was carried out by purposive random sampling, in which the researcher took respondents based on specific objectives, namely unit leaders in various types of organizations (manufacturing, production and sales). There are 2 medium scale organizations (based on the number of employees moving from 100-1000) that participated in this study. PT Mayasari, in the city of Bandung, and PT. Toyogiri is in the city of Bekasi. PT Mayasari is engaged in bread making services (production and sales, shops spread across Bandung and its surroundings), has 324 employees for all parts of both production and branches. PT. Toyogiri, in collaboration with companies in South Korea and China, is engaged in the manufacture of steel in Bekasi. The number of employees is 870 people. Production is shipped throughout Indonesia.

The procedure for determining the organization is based on the willingness of the organization to be the research site. Another consideration is that the organization has a work unit which operationally has a coordinator, section head, section head or supervisor.

Measurements for all variables are the result of adaptation of existing measurements and are used in a research framework for science development.

Self knowledge is measured by a combined scale of self-concept and self-confidence. There are 8 items related to self-understanding of individual values / expectations, beliefs and behavior.

Self consistency is measured by the Preference of Consistency Scale. In particular, internal consistency is used because it accesses efforts to get consistency between intentions / expectations, beliefs and behaviors.

The psychological capital scale has 1) having the confidence (self efficacy) to take and make an effort necessary for the success of the task at hand, 2) giving a positive response (optimism) for present and future success, 3) being diligent and persistent in the goals and objectives and if necessary, rearrange efforts towards the goal (hope) in order to achieve success and 4) if faced with problems and failures persist 4) if faced with problems and failures persist and bounce back and even stronger.

There are two types of evidence collected in order to check the validity of the measuring 
instrument, namely evidence related to the test content and related to the internal structure of the test

The analysis of the reliability of the measuring instrument used is internal consistency, which is the consistency between the parts in the test. The reliability coefficient is obtained when testing the correlation of each item with the total score. Analysis of this reliability was carried out on 110 respondents. Overall the reliability of this research measuring instrument was at a high and very high level.

The stage before analyzing the data was to perform the assumption test, normality test, homogeneity test, outlier test and multicollinearity test. Hypothesis testing (authentic leadership antecedents) using the Structural Equation Model (SEM) method with the help of the AMOS version 20 program. The purpose of this analysis is to test the hypothesis proposed in this study.

Confirmatory modeling strategy was chosen as the model in this study because the researcher only has a single model consisting of a series of relationships and uses SEM to assess how well the proposed model fits empirical data.
The basic assumption of SEM is that the data is normally distributed and the estimation technique used is maximum likelihood. This technique was chosen because under ideal conditions, this technique still provides stable and valid results with a sample size as small as fifty samples and is not biased when the assumption of multivariate normality is met [14]

\section{RESULT}

Respondents in this study were female employees who have subordinates (sie, unit, division, organizational department in Bandung and Bekasi. The total number of respondents who filled the entire scale was 110 people. The number that could be analyzed was 110 employees. Based on gender, there are 58 (53\%) male employees and 52 (47\%) female employees

Estimation of the reliability of research data on 110 respondents was carried out using the Cronbach Alpha statistical test. The results can be seen in the table 1 .

Table 1. Reliability coefficient

\begin{tabular}{|l|c|c|}
\hline \multicolumn{1}{|c|}{ Variable } & Reliability coeficient & Meaning \\
\hline Authentic Leadership & 0,93 & high \\
\hline Self consistency & 0,866 & high \\
\hline Selfknowlege & 0,937 & high \\
\hline Psycap & 0,953 & high \\
\hline Org and family com percpt & 0,896 & high \\
\hline
\end{tabular}

The validity of research data on 110 respondents is known from the size of the load of each observed variable that forms the latent variable. Data is said to be valid if it has a factor load $>0.5$ [15]. The factor load of all variables that meet the requirements is called valid.

The results of multivariate testing on this research data produce normal data on authentic and antecedent leadership. This is shown by the Komogorov Smirnov normality test, see table 2.

The multicollinearity test results for authentic and antecedent leadership showed no correlation between independent variables. This is indicated by the statistically justified error rate (tolerance> 0.10 ) and the squared standard deviation inflation factor (VIF> 0.10). The results can be seen in the table 3 .

The results of this study indicate that the antecedent theoretical model hypothesized in this study is in accordance with the empirical data. The suitability of the antecedent model can be seen in the figure 1 . The suitability of the theoretical model with empirical data is shown by the fulfillment of all the goodness of fit (GoF) criteria, as shown in the table 4. 
Table 2. Normality test

\begin{tabular}{|l|l|l|l|}
\hline \multicolumn{1}{|c|}{ Variable } & Coefficient & Asym sig & Meaning \\
\hline Auth lead & 0,678 & 0,747 & normal \\
\hline Self consistency & 0,806 & 0,535 & normal \\
\hline Selfknowlege & 1,035 & 0,235 & normal \\
\hline Psycap & 1,106 & 0,173 & normal \\
\hline
\end{tabular}

Table 3. Tolerance values and VIF

\begin{tabular}{|l|l|l|l|}
\hline \multicolumn{1}{|c|}{ Variable } & Tolerance & VIF & Meaning \\
\hline Psycap & 0,862 & 1,161 & No multicollearity \\
\hline Selfkcons & 0,732 & 1,367 & No multicollearity \\
\hline Selfknow & 0,82 & 1,219 & No multicollearity \\
\hline
\end{tabular}

Table 4. Godness of Fit (GoF) Structural Model Parameters

\begin{tabular}{|l|l|l|l|}
\hline Parameter & Gof & c.r & meaning \\
\hline Chi -Square & 95,257 & small & high \\
\hline P & 0,09 & $\geq .0,05$ & high \\
\hline RMSEA & 0,045 & $\leq 0,08$ & high \\
\hline CFI & 0,977 & $>0,90$ & high \\
\hline GFI & 0,901 & $>0,90$ & high \\
\hline AGFI & 0,848 & $\geq 0,09$ & moderate \\
\hline TLI & 0,969 & $>0,09$ & high \\
\hline
\end{tabular}

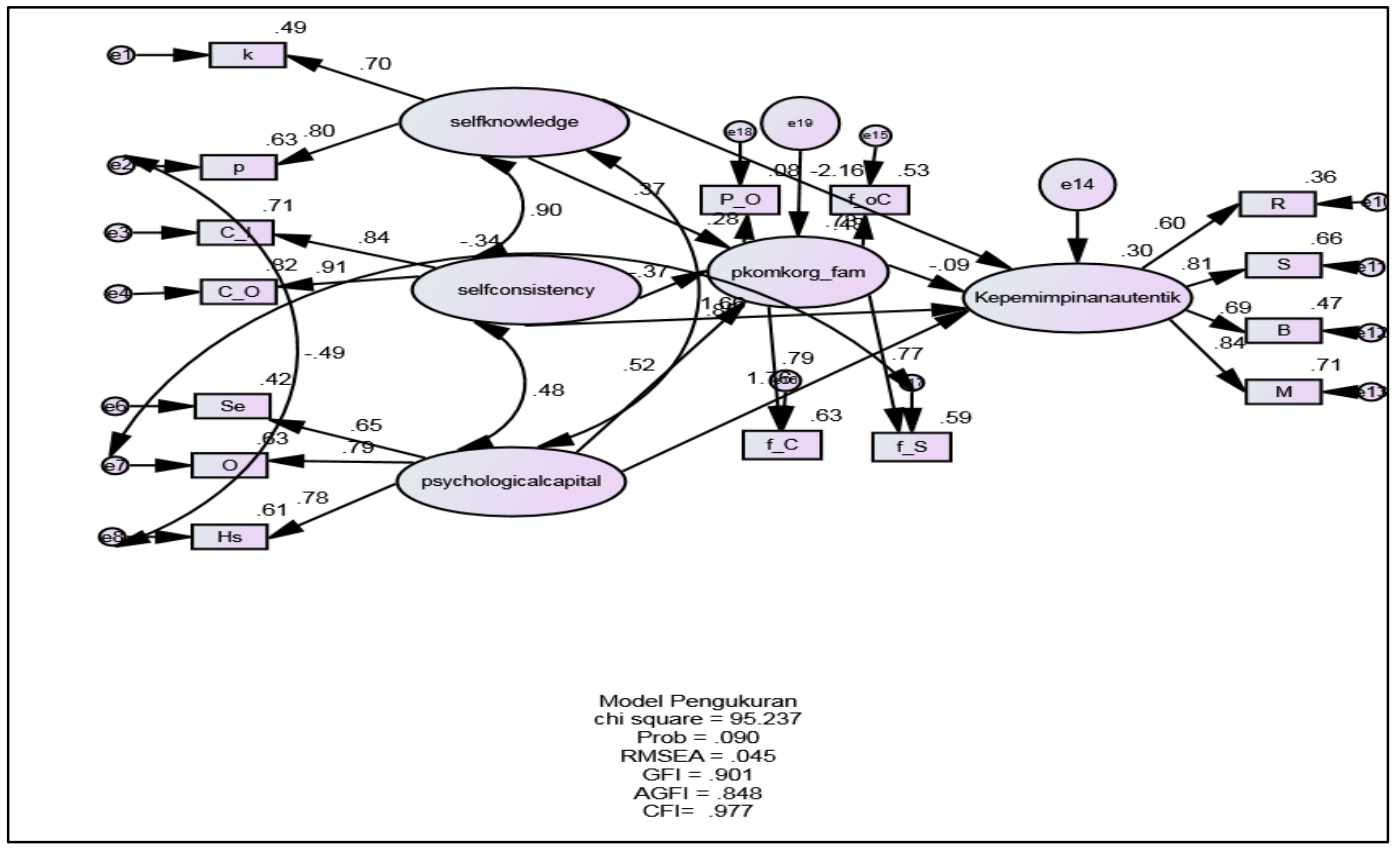

Figure 1. The measurement model of authentic leadership antecedents 


\section{DISCUSSION}

Based on the results of testing the first hypothesis, it is shown that authentic leadership can be explained through the emergence of selfknowledge variables, self-consistency variables and psychological capital and perceptions of communication in organizations and families acting as mediators.

The results of this study indicate that the theoretical model of self-knowledge, self consistency and psychological capital and authentic leadership assertions as a mediator with authentic leadership is in accordance with empirical data. These results corroborate previous findings related to theoretical and conceptual studies. The antecedents of these three variables were selfknowledge, self-consistency and psychological capital which were relatively larger. These three variables have a direct relationship that is greater than the indirect relationship. This is also confirmed by only the psychological capital variable which is significant and positively associated with authentic leadership. Even so, the hypothesis finding that psychological capital can be antecedent implies that the role of psychological capital is quite influential on authentic leadership

The role of organizational and family communication perceptions in this study is not significant enough to act as a mediator because the correlation between variables is higher in direct relationships. In this context there are several concerns related to the role of organizational and family communication perceptions, especially related to measurement tools. Perception measurement tool of organizational communication (has 1 item) and perception of communication in family has 3 items. The representation of this item is not significant enough to influence the emergence of item leadership. Therefore, further research pays attention to indicators of measuring perceptions of organizational and family communication.

This study shows that the role of perceptual communication in organizations and families does not directly affect authentic leadership. Antecedents of self-knowledge, self-consistency and psychological capital play a more direct role in influencing the formation of authentic leadership than through perceptions of organizational and family communication leadership.

\section{CONCLUSION}

The theoretical model of authentic leadership could be explained by self-knowledge, self consistency and psychological capital and authentic leadership assertions as a mediator. Self-knowledge, selfconsistency and psychological capital have a direct relationship toward authentic leadership.

\section{AUTHORS' CONTRIBUTIONS}

This study provides an alternative in understanding authentic leadership through the perspective of the perceived role of organizational and family communication as a mediator. This role has no significant relationship. The role of antecedents (self knowledge, self consistency and psychological capital) has a significant relationship with authentic leadership.

\section{ACKNOWLEDGMENTS}

Researchers would like to thank the promoter team from the Department of Psychology, University of Surabaya, Indonesia, the Institute for Research and Community Service, University of Sanata Dharma and the Faculty of Psychology, University of Sanata Dharma, Indonesia for funding this research.

\section{REFERENCES}

[1] A. Caza, B. Jackson, Authentic leadership ( $p$. 352 -364). In The SAGE handobook of leadership. (eds) Bryman, A., Collinson, D., Grint, K., Jackoson, B \& Uhl-Bien, M. Los Angeles: Sage Pub., 2011.

[2] V. Ratanjee. M. Wu, Why Indonesia needs authentic leadership?.Gallup Business Journal. Articles. 2013.

[3] K. Petersen, C.M. Youssef-Morgan, The "left side" of authentic leadership: contributions of climate andpsychological capital. Leadership \& Organization Development Journal,2018 Vol. 39 No. 3, pp. 436-452, Emerald Publishing Limited 0143-7739. DOI 10.1108/LODJ-062017-0171

[4] J.A. Crawford, S. Dawkins, A. Martin, G. Lewis, Putting the leader back into authentic leadership: econceptualising and rethinking leaders. Australian Journal of Management, 2020, 45(1), 114-133. DOI: $10.1177 / 0312896219836460$ 
[5] H. Leroy, Y. Palanski, T. Simons, Authentic leadership and behavioral integrity as drivers of follower commitment and performance. Journal of Business Ethics, 2012, 107: 255264.

[6] C.S. Cervo, L. dos S. Mónico, M.N. dos S. Rebelo, C.S. Hutz, L, Pais, L., Authentic Leadership Questionnaire: invariance between samples of Brazilian and Portuguese employees .Psicologia: Reflexão e Crítica ,2016, 29:40. DOI 10.1186/s41155-016-00464

[7] L. Monzani, S. Braun, V.R. Dick, It takes two to tango: The interactive effect of authentic leadership and organizational identification on employee silence intentions. German Journal of Human Resource Management, 2016, Vol. 30(3-4)246-266.DOI:

10.1177/2397002216649896gjh.sagepub.com

[8] A. Emuwa, Dail, Authentic leadership as a contemporary leadership model applied in Nigeria Fields, African Journal of Economic and Management Studies, Vol. 8 No. 3, 296313 (C) Emerald Publishing Limited 2040-0705 DOI 10.1108/AJEMS-06-2016-0092Received 1 July 2016 Revised 16 November 2016 Accepted 3 February 2017, School of Business and Leadership, Regent University, Virginia Beach, Virginia, USA

[9] S-G. Liang, Linking leader authentic personality to employee voice behavior: a multilevel mediation model of authentic leadership development. European Journal of Work and Organizational Psychology, 2017. DOI: 10.1080/1359432X.2017.1293656 (thd voice behavior)

[10] F. Andrianto, I.Z. Ratnaningsih, Hubungan Antara Gaya Kepemimpinan Autentik dengan Keterikatan Kerja Pada Perawat Rumah Sakit "X" Semarang. Jurnal Empati, April 2018, Volume 7 (Nomor 2), halaman 252-258.

[11] B. Alilyyani, C.A. Wong, G. Cummings, Antecedent, Mediators, and Outcomes of Authentic Leadership in Healthcare: A Systematic Review. International Journal of Nursing Studies, 2018. DOI: https://doi.org/10.1016/j.ijnurstu.2018.04.001

[12] C. Peus, J.S. Wesche, B. Streicher, S. Braun, D. Frey, Authentic Leadership: An Empirical Test of Its Antecedents, Consequences, and Mediating Mechanisms. Journal of Bus Ethics,
2017, 107 (3):331-348. DOI 10.1007/s10551011-1042-3

[13] S. Braun, K.W.A.M. Nieberle, Authentic leadership extends beyond work: A multilevel model of work-family conflict and enrichment. The Leadership Quarterly, 2017.

[14] J.F. Hair, W.C. Black, B.J. Babin, R.E. Anderson, R.L Tatham, Mulitivariate data analysis. 6th Ed. New Jersey: Pearson Prentice Hall. 2006 